\title{
O BELO ENQUANTO CONGRUENTIA PARTIUM: A HARMONIA NA BELEZA SENSÍVEL EM SANTO AgOSTINHO
}

\author{
Ricardo Evangelista Brandão ${ }^{1}$ \\ Instituto Federal de Pernambuco (IFPE) \\ https://orcid.org/0000-0003-2217-4661
}

\begin{abstract}
RESUMO:
Uma boa parte dos textos que versam acerca da beleza em Agostinho tem, como pano de fundo os ataques à beleza do mundo desenvolvido pelos maniqueus. Assim, o pensador objetivando defender a tese de um cosmos belo, procura construir uma definição de beleza sensível deveras ampla, que possa abarcar criaturas aparentemente despidas de beleza segundo a ótica humana. No presente artigo, estudaremos a categoria do belo da congruentia partium, que nosso filósofo desenvolve em uma definição da beleza sensível, expostas em dois textos, notadamente a Epístola III e no Sobre a Cidade de Deus. Nos mencionados textos, o pensador parte da estrutura da definição de beleza enquanto simetria apresentada pelo filósofo Cícero em sua obra Tusculanae Disputationes, todavia, utiliza-a para teorizar um conceito de congruentia partium, conceito esse bem mais amplo que a simetria, e, portanto, mais útil ao debate que ele enfrentava.
\end{abstract}

PALAVRAS-CHAVE: Beleza sensível; Harmonia; Mundo.

\section{THE BEAUTIFUL AS CONGRUENTIA PARTIUM: THE HARMONY IN THE SENSITIVE BEAUTY IN ST. AUGUSTINE}

\begin{abstract}
:
A good part of the texts that speak about the beauty in Augustine has, as a background, the attacks on the beauty of the world developed by the Manichaeans. Thus, the thinker, aiming to defend the thesis of a beautiful cosmos, seeks to construct a definition of a very wide sensitive beauty, which may encompass creatures seemingly naked in beauty according to the human perspective. In this article, we will study the category of the beautiful of the congruentia partium, which our philosopher develops in a definition of sensible beauty, exposed in two texts, notably Epistle III and in On the City of God. In the mentioned texts, the thinker starts from the structure of the definition of beauty as symmetry presented by the philosopher Cicero in his work Tusculanae Disputationes, nevertheless, it uses it to theorize a concept of congruentia partium, a concept that is much broader than the symmetry, and therefore, More useful to the debate he faced.
\end{abstract}

KEYWORDS: Sensitive beauty; Harmony; World.

1 Doutor em Filosofia pela Universidade Fedral de Pernanbuco (UFPE), Pernambuco - Brasil. Professor de Filosofia do Instituto Federal de Pernambuco (IFPE), campus Belo Jardim, Pernambuco - Brasil. E-mail: ricardobrand75@gmail.com

BRANDÃO, Ricardo Evangelista. O belo enquanto congruentia partium: a harmonia na beleza sensível em Santo Agostinho. Griot : Revista de Filosofia, Amargosa, Bahia, v.16, n.2, p.322-333, dezembro/2017. 


\section{Introdução}

Agostinho de forma insistente ao longo de sua imensa obra, investiga um conceito de beleza sensível apto para refutar os desacatos à beleza e perfeição do mundo, feito pelos maniqueus ${ }^{2}$. Nessa busca, o pensador parte da estrutura da definição de beleza enquanto simetria apresentada pelo filósofo Cícero em sua obra Tusculanae Disputationes, todavia, utiliza-a para teorizar um conceito bem mais amplo que a simetria, e portanto, mais útil ao debate que ele enfrentava. No transcorrer de nossa análise perceberemos que a base da definição permanecerá, porém, com intenção absolutamente distinta de tribuno, pois adaptou a definição ao debate que enfrentava, formando assim o conceito de congruentia. O mencionado conceito, como veremos, embora possa também ser traduzida como simetria, no contexto em que o pensador cristão o usa, o mais apropriado é traduzi-lo com um

2 Um problema fundamental na cosmologia de Santo Agostinho, que de certa forma delimitou e delineou seu o conceito de beleza sensível, foi um problema levantado pelos maniqueus acerca da fealdade e maldade natural do cosmos. Já adiantamos que o feio e o mal destacados pelos oponentes de Agostinho, na medida em que estão relacionados com as criaturas que compõe o cosmos, se referem às criaturas não morais principalmente, assim, este feio e mal não é moral, mas trata-se de deformações estéticas na aparência no caso da fealdade, e na funcionalidade apropriada desses entes no caso da maldade. Neste preciso caso, sem dúvida, o feio na medida em que é na compreensão dos de Mani uma deformação estética, é um desvelar da maldade natural do cosmos. E igualmente nesse sentido, quando um ente do mundo não possui uma funcionalidade que eles entendem ser apropriada, em sua má funcionalidade é feio. No mesmo caminho em sua refutação segue Agostinho. Nesse caso, o belo está relacionado com a forma estética das criaturas, mas também é uma manifestação da bondade natural do cosmos, que igualmente não é bondade moral, visto que a maior parte dos componentes do mundo não são seres morais. Portanto, a bondade de cada ente da natureza no presente debate, trata-se do cumprir o propósito para o qual foi designado no ato da criação pelo Criador (Cf. De Gen. contra man, I, 16, 25; RUBIO, 2008, p. 80; ; TORRENTES, 2008, p. 57 60; PUECH, 2006, p. 37). A cosmologia maniqueia é em síntese a história da união e separação de dois princípios ontológicos, mais comumente denominados de Luz e Trevas, que se dá em três tempos. No primeiro tempo antes da existência do universo, havia o dualismo radical entre os dois princípios ontológicos, a luz e as trevas, ambos são ingênitos, eternos e absolutamente separados, logo um não proveio e não é anterior ao outro, e nesta fase inicial não possuíam nenhuma relação (Cf. RUBIO, 2008, p. 80; _ _ TORRENTES, 2008, p. 57-60). Cada um existia em regiões simetricamente separadas, a luz ao norte e as trevas ao sul. Ambos são uma espécie de reino com um governante, o reino da luz tem como chefe o Príncipe da luz (também denominado por Deus, Pai da Grandeza, Bem, etc.). As trevas são presididas pelo Príncipe das Trevas (igualmente denominado de Rei das Trevas, Arque demônio, Mal, Matéria, etc.). Trevas e luz, como os próprios nomes já revelam são ontologicamente contrários, não existindo nada em comum entre eles a não ser o fato de possuírem a mesma quantidade de poder. No tempo médio, ou segundo momento, rompe-se a dualidade inicial primitiva como consequência da luta entre essas duas forças. Pois, por motivo de inveja do Príncipe das Trevas em relação à beleza do reino da Luz, as Trevas intencionaram invadir e engolir parte do reino que lhe limitam ao norte (Cf. COSTA, 2003, p. 51, 52; PUECH, 2006, p. 37). Na luta entre os dois reinos, as trevas capturam parte da Luz, e decorrente dessa mistura emana o mundo sensível. Primeiramente dessa mistura são emanados o céu e a terra, depois as árvores, os animais e os homens. Portanto, o universo é resultado da mescla entre Luz e Trevas tanto em sua origem como em sua constituição, tendo em si elementos dos dois princípios ontológicos originários, sendo assim, partícipe das mesmas substâncias dos referidos princípios. Dessa forma, a presença de criaturas feias e nocivas no cosmos, na compreensão dos discípulos de Mani, são a prova de que o feio ou o mal, e a beleza ou o bem, estão misturados na natureza, e que, por conseguinte, o mundo não foi formado por um único Deus como afirmava Agostinho.

BRANDÃO, Ricardo Evangelista. O belo enquanto congruentia partium: a harmonia na beleza sensível em Santo Agostinho. Griot : Revista de Filosofia, Amargosa, Bahia, v.16, n.2, p.322-333, dezembro/2017. 
termo que conceitualmente é mais amplo que a simetria, de forma que em certo sentido a engloba. A definição que analisaremos doravante é importante para o filósofo cristão, pois ele a formulará no começo de sua vida cristã (na Epístola III) e a repetirá em um momento de maior maturidade (no Sobre Cidade de Deus), quando já era bispo de Hipona, é óbvio que essa definição foi utilizada nos dois textos sob contextos absolutamente diferentes, versando sobre distintos problemas.

\section{Breve análise da congruentia partium na epístola III}

Nos primeiros meses de conversão cristã, estando no retiro filosófico teológico de Cassicíaco Agostinho escreveu suas primeiras cartas, contendo desde assuntos de ordem pessoal, até temas doutrinários, filosóficos e teológicos ${ }^{3}$. $\mathrm{O}$ fragmento sob o qual nos debruçaremos encontra-se na sua terceira carta, escrita no ano 387, endereçada a seu amigo Nebrídio. Na citada epístola, o filósofo africano entre assuntos vários, opina acerca da realidade inteligível e sensível defendidas por filósofos de linhagem platônica. Ao constatar que para os citados pensadores o que é inteligível é superior ao sensível (Cf. Epist., III, 2), objetivando aplicar esse raciocínio na valoração ontológica distinta entre o corpo sensível e a alma imaterial, nos traz uma definição de beleza sensível na fase de pensamento da qual nomeamos de pós maniqueia ${ }^{4}$ :

De que consistimos? De alma e corpo. Qual deles é melhor? Sem dúvida, a alma. O que louvamos no corpo? Não vejo outra coisa que a beleza. O que é a beleza do corpo? Harmonia das partes, com certa suavidade de cor. Aonde é melhor essa forma de beleza e onde é falsa? Quem duvida que é ali, onde é autêntica. E onde é autêntica? Sem dúvida na alma. Por conseguinte, temos que amar mais a alma que o corpo (Epist., III, 3, 4) $)^{5}$.

\footnotetext{
${ }^{3}$ Com trinta e três anos de vida e aproximadamente três meses de conversão, no outono de 386 , Agostinho com sua mãe, filho, alunos e alguns amigos se hospedaram em uma chácara em Cassicíaco de propriedade de seu amigo Verecundo, passando ali seis ou sete meses (Cf. CAPANAGA, 1994, p. 397-398). Nesse retiro filosófico-teológico Agostinho discutiu com seus companheiros acerca de vários problemas filosóficos, gerando assim a carta que comentaremos no corpo do texto, e quatro obras em formato de diálogos: Contra Acadêmicos, Sobre a Vida Feliz, Sobre a Ordem e o Solilóquios.

${ }^{4}$ Utilizamos a expressão "fase pós maniqueia", se referindo aos escritos em que Agostinho escreveu após o abandono do maniqueísmo. Sabemos por revelação feita pelo pensador nas Conf. IV, 13, 20; 15, 24, que ele escreveu um único texto na fase maniquéia, notadamente, o De pulchro et apto, obra essa que também traz uma definição de beleza, mas que sabemos pouco dela pois trata-se de uma obra perdida. Tudo o que possuímos dessa obra perdida, são apenas fragmentos citados por Agostinho vinte anos depois de escrever a obra, nas Confissões (Cf. Conf. IV, 13, 20; 15, 24).

${ }^{5}$ Unde constamus? ex animo et corpore. quid horum melius? uidelicet animus. quid laudatur in corpore? nihil aliud uideo quam pulchritudinem. quid est corporis pulchritudo? congruentia partium cum quadam colorís suavitate. haec forma ubi uera melior, an ubi falsa? quis dubitet, ubi uera est, esse meliorem? ubi ergo uera est? in animo scilicet. animus igitur magis amandus quam corpus (Epist., III, 3, 4-PL 33). Todas as obras de Santo Agostinho citadas ao longo do presente artigo, seguem a versão bilíngue da coleção Obras Completas de San Agustin, traduzidas e publicadas pela Biblioteca de Autores Cristiano (BAC), que por sua vez utilizou a versão latina da Patrologiae Latinae Elenchus (PL). A tradução para o vernáculo foi feita por nós a partir do texto espanhol, presente na citada coleção bilíngue, gotejada com o texto latino da mesma.
}

BRANDÃO, Ricardo Evangelista. O belo enquanto congruentia partium: a harmonia na beleza sensível em Santo Agostinho. Griot : Revista de Filosofia, Amargosa, Bahia, v.16, n.2, p.322-333, dezembro/2017. 
Na perícope citada, o hiponense com a intenção de afirmar a tese de que o corpo é inferior a alma, baseando-se no pensamento neoplatônico de que as verdades inteligíveis, não materiais, espirituais, etc, são superiores às realidades materiais, sensíveis, corpóreas, etc., afirma que diferentemente da alma que possui inteligência, no corpo a única coisa passível de admiração é a sua beleza (nihil aliud video quam pulchritudinen). Talvez não devamos interpretar essa afirmação de forma literal, como se o corpo não tivesse outra qualidade que não a beleza, pois, se assim fosse Agostinho estaria ignorando uma das principais funções do corpo, que é a sua utilidade de ser o perfeito veículo para exprimir as ações da alma no mundo sensível ${ }^{6}$. Mas, possivelmente, retórico que era, esteja simplesmente querendo ressaltar o que segundo a sua opinião, é o atributo mais admirado do corpo.

Seja como for, o fato é que o filósofo permanece com a ideia do De pulchro et apto de que somos atraídos pelo que é belo, na medida em que o que mais chama a nossa atenção nos corpos é a sua beleza ${ }^{7}$, e assim como na obra perdida a pergunta ressurge: "Quid est corporis pulchritudo?" (O que é a beleza do corpo?). Note que no De puchro et apto, na medida em que a pergunta era feita em uma perspectiva maniqueia, Agostinho não teve a necessidade de esclarecer de que tipo era a beleza da qual investigava "Quid est ergo pulchrum? Et quid est pulchritudo?" (Conf., IV, 13, 20). Pois, a única beleza possível naquele momento teórico do filósofo era a corpórea ou sensível. Com o abandono da cosmovisão maniqueia, e consecutivamente a aproximação ao neoplatonismo e ao cristianismo, nosso pensador sente a necessidade de expor implicitamente em seus textos que não era mais materialista. E mais, torna-se uma questão de honra provar que a matéria sensível é inferior a realidade espiritual, pois, quando maniqueu fez bastante uso de sua agudeza intelectual e retórica para convencer a muitos amigos que no materialismo dualista maniqueu poderiam encontrar a verdade. Logo, o texto que ora nos debruçamos implicitamente está sendo guiado pelo debate antimaniqueu, pois, não podemos esquecer que a ideia central do texto é provar que a alma não material é superior ao corpo material ${ }^{8}$.

${ }^{6} \mathrm{O}$ filósofo de Hipona, apesar de insistir na superioridade da alma frente ao corpo, afirma a superioridade do corpo humano frente ao mundo sensível, pois, até mesmo em sua substância material o homem é um reflexo especial da divindade, visto que ainda que a animalidade humana esteja no corpo, essa animalidade não é como a de qualquer animal, mas como formada especialmente para ser animada por uma alma que é imagem de Deus. $O$ corpo humano com todo o seu complexo aparato orgânico serve perfeitamente para dar vazão à expressão sensível da alma humana (Cf. De Gen. ad. litt., VI, 12, 22).

${ }^{7}$ Eis o texto que Agostinho relembra a pergunta acerca do belo do De pulchro et apto nas Confissões: “Naquela época eu não sabia e amava as belezas inferiores. Caminhava para o abismo e dizia a meus amigos: “Acaso amamos alguma coisa senão o belo? Que é o belo? Que é a beleza? Que é que nos atrai e afeiçoa aos objetos que amamos? Se não houvesse neles certo ornato e formosura não nos atrairiam"" - "Haec tunc non noveram et amabam puchra inferiora et ibam in profundum et dcebam amicis meis: 'Num amamus aliquid nisi pulchrum? Quid est ergo puchrum? Et quid est puchritudo? Quid est quod nos allicit et conciliat rebus, quas amamus? Nisi enim esset in eis decus et species, nullo modo nos ad se moverent" (Conf., IV, 13, 20 - PL 32).

${ }^{8}$ Pensamento absolutamente estranho a cosmovisão que Agostinho se afastara havia poucos anos, que não aceitava a ideia do imaterial, nem da alma que era uma matéria sutil, nem mesmo de Deus. Pois, o maniqueísmo do qual o hiponense foi adepto por nove anos, era materialista, pois, apesar de segundo os relatos mitológicos maniqueus apenas o Príncipe das Trevas seja designado como matéria,

BRANDÃO, Ricardo Evangelista. O belo enquanto congruentia partium: a harmonia na beleza sensível em Santo Agostinho. Griot : Revista de Filosofia, Amargosa, Bahia, v.16, n.2, p.322-333, dezembro/2017. 
Devido a isso, Santo Agostinho imbuído por categorias filosóficas - teológicas que dão conta do material e do imaterial necessita explicitar qual tipo de beleza ele vai tratar de definir: "Quid est corporis pulchritudo?". No contexto da questão o Pensador disserta acerca da diferença ontológica do corpo e da alma, nos conduzindo assim a traduzir corporis pulchritudo como beleza do corpo, corpo no sentido de corpo humano. Todavia, visto que o substantivo latino corpus pode significar além de corpo humano, qualquer substância sensível, entendemos que a despeito do fato de que o hiponense estivesse indagando sobre a beleza do corpo humano, não seria nenhuma violência textual estender tal pergunta aos demais corpos ou substâncias sensíveis, pois, ao menos no aspecto estético não há grandes distinções entre o corpo humano e as demais substâncias materiais, a não ser em sua gradação de beleza. Além disso, a própria definição dada seguindo a pergunta, cabe sem problemas a qualquer substância material ou sensível, de maneira que podemos traduzir não literalmente e hermeneuticamente orientados, a pergunta latina sem agressão ao texto original como: $\mathrm{O}$ que é a beleza sensível?

Destarte, o pensador cristão nos traz a seguinte definição de beleza sensível: "congruentia partium cum quadam coloris suavitate" (harmonia das partes com certa suavidade de cor). $\mathrm{O}$ termo latino congruentia pode ser traduzido por conveniência, congruência, conformidade, simetria e harmonia (Cf. SARAIVA, 2006, p. 283). Todavia, a palavra portuguesa que menos cabe na tradução segundo o contexto é a simetria ${ }^{9}$. A simetria informa acerca da igualdade das partes de um corpo, e ao menos no texto de nossa análise ela não é a mais apropriada para traduzir congruentia, porque a mesma definição é utilizada em seguida para afirmar a beleza mais autêntica da alma, não fazendo assim o menor sentido se traduzíssemos congruentia como simetria nesse texto, por não haver coerência em se pensar em uma alma simétrica, pois, sendo ela imaterial não é composta de partes para ter igualdade de partes. $\mathrm{O}$ mesmo não acontece se traduzirmos a palavra latina em questão por harmonia, pois, ao menos tirando o peso do sentido literal da palavra, poderia informar acerca da beleza da alma enquanto harmonia. Pois, nesse caso a alma seria harmônica com suas diversas faculdades, portanto, na alma a mente se harmoniza com o conhecimento, que se harmoniza com o amor, tornando a alma bela, e a

o Rei da Luz também é de natureza física, visto que um Deus é limitado pelo outro. Como esclarece Marcos Costa (2003, p. 159): “A luz expande-se ilimitadamente para cima, para o norte, o leste e o oeste, enquanto as trevas expandem-se ilimitadamente para baixo e para o sul. Estas duas forças fazem limite e bloqueiam-se mutuamente onde se encostam (fazem fronteira)".

9 Similitudine (semelhança), aequalitas (igualdade) e congruentia (harmonia) são conceitos chave na beleza das formas sensíveis das criaturas em Santo Agostinho, a despeito do fato de serem termos muito próximos conceitualmente, e segundo a língua latina poderem ser usados como sinônimos dependendo do contexto de seu uso, pensamos que cada um desses vocábulos revela algo diferente embora complementar da estética do filósofo. Os três termos são indistintamente traduzidos por tradutores na língua portuguesa como simetria, e embora não seja totalmente ilegítima essa tradução, na medida em que na definição de simetria a espaço para esses três usos, a simetria é mais propriamente entendida tanto pela tradição como pelo uso contemporâneo do termo como igualdade das partes (aequalitas).

BRANDÃO, Ricardo Evangelista. O belo enquanto congruentia partium: a harmonia na beleza sensível em Santo Agostinho. Griot : Revista de Filosofia, Amargosa, Bahia, v.16, n.2, p.322-333, dezembro/2017. 
despeito de ter várias faculdades a relação harmônica a faz una (Cf. De Trin., IX, 5, $8)^{10}$.

Neste caso, a beleza sensível é a harmonia das partes. Temos nessa definição um conceito bastante amplo de beleza, visto que, se a beleza fosse simétrica (aequalitas), só a exata igualdade das partes tornaria um corpo belo, e já que a harmonia é a disposição bem ordenada entre as partes de um todo, o simétrico embora não seja o único padrão de beleza, é ele também belo, na medida em que a sua exata igualdade das partes também é uma disposição bem ordenada das partes de um todo.

De maneira concreta essa harmonia das partes se dá no equilíbrio de um determinado ente da Natureza. Ou seja, essa congruentia se dá quando as partes de um corpo que estão em relação harmônica umas com as outras, não sendo demasiadamente grandes e tão pouco demasiadamente pequenas, quando as citadas partes são comparadas. Se por um lado, a exata igualdade das partes (simetria) não é obrigatoriamente requerida nesta definição, por outro lado, a demasiada desproporção de forma que desagrade ao contemplador não cabe na mesma. Portanto, mesmo havendo alguma diferença entre as partes, o que é muito natural nos entes ônticos, essas diferenças se não chocam por sua grandeza, sendo aos nossos olhos deformadas, contribuem harmoniosamente para a beleza de um corpo.

\section{Breve análise da congruentia partium no sobre a cidade de deus}

Para corroborar a nossa interpretação, convém estudarmos o texto análogo de De civitate Dei contra paganos. No fragmento que citaremos em seguida, Aurélio Agostinho defende a doutrina cristã da ressurreição, contra críticos da citada doutrina que questionavam entre outras coisas, como acontecerá a ressurreição dos corpos de pessoas deformadas ${ }^{11}$. Para responder a esta indagação, o filósofo repetirá

10 No tratado Sobre a Trindade, Santo Agostinho no intuito de explicar a unidade substancial e diversidade de pessoas da Trindade, busca diversos exemplos na natureza interna e externa do homem para tentar tornar um pouco mais compreensível para a mente humana tão difícil mistério divino. É nesse contexto que se encontra o texto referido no corpo de nosso trabalho, pois, assim como a alma humana possui uma harmonia tal que mesmo composta de diversas faculdades, e cada uma dessas faculdades serem distintas em suas funções, elas formam uma única alma devido a sua harmoniosa mútua relação em cada função que desempenha, de maneira semelhante acontece com a Trindade, em que as três pessoas (Pai, Filho e Espírito Santo) apesar de distintas e de se imbuírem de funções distintas, cada pessoa harmoniosamente participa da função da outra, visto que embora distintas em suas pessoalidades, são uma única natureza divina, um único Deus (Cf. De Trin., IX, 1, 1- 12, 18).

${ }^{11}$ No contexto da passagem (que vai desde XXII, 11, 1 até XXII, 25 da De civitate Dei) o problema a ser resolvido são dúvidas acerca da ressurreição do corpo, dúvidas trazidas por fiéis e por principalmente críticos da citada doutrina, que Agostinho chama de calúnias burlescas dos infiéis (Cf., De civ. Dei, XXII, 12, 1). No contexto imediato da passagem que analisaremos no corpo do texto, nosso pensador responde em síntese a seguinte questão: como se dará a ressurreição de uma pessoa que possui um corpo deformado, o corpo também será ressurreto deformado, visto que a escritura afirma que Deus conta todos os cabelos da cabeça do homem, e que portanto nada se perderá? Agostinho enfaticamente responderá que fealdade alguma haverá no céu, logo, os corpos que são fisicamente deformados aqui na terra, na ressurreição serão transformados e consecutivamente todas as deformações serão postas em harmonia. Na ressurreição os corpos serão transformados, e nessa transformação as deformações serão aniquiladas, de maneira que as pessoas receberão seus corpos

BRANDÃO, Ricardo Evangelista. O belo enquanto congruentia partium: a harmonia na beleza sensível em Santo Agostinho. Griot : Revista de Filosofia, Amargosa, Bahia, v.16, n.2, p.322-333, dezembro/2017. 
a definição de beleza da carta três, com pequenas, porém importantes diferenças que lançarão luzes sobre o nosso objeto. Eis o texto: "A beleza do corpo é a harmonia de suas partes com certa suavidade de cor. Aonde não há harmonia das partes existe algo que ofende, ou porque é disforme, ou porque é pouco, ou porque é demasiado" (De civ. Dei, XXII, 19, 2) ${ }^{12}$.

O texto citado não deixa dúvidas com relação ao que Agostinho quer dizer com partium congruentia (congruência ou harmonia das partes). A explicação desses termos está logo em seguida: "ubi autem non est partium congruentia, aut ideo quid offendit" (aonde não existe harmonia das partes, existe algo que ofende). Levando em consideração que o autor discorre acerca da beleza sensível, o offendit nesse contexto explicita uma ofensa aos sentidos, algo que incomoda em nosso contemplar estético, que é inconveniente esteticamente.

E o que é isso que nos ofende quando as criaturas não possuem a partium congruentia? É justamente "quia pravum est, aut ideo quia parum, aut ideo quia nimium". Corroborando a nossa interpretação da carta três, o harmonioso é o que não é pravum, que podemos traduzir como torto, defeituoso, disforme, mal. Embora a tradução brasileira do De civitate Dei ${ }^{13}$, traduzir pravum como mal, pensamos que essa é a palavra menos apropriada para traduzir o termo latino em questão. Pois, em toda a sua cosmologia, Agostinho defenderá contra os maniqueus a tese da bondade natural do cosmos, logo, se aqui nesse fragmento traduzíssemos o citado termo por mal, teríamos nessa perícope uma contradição em sua cosmologia, visto que estaríamos concedendo que na natureza o mal seja algo natural.

Portanto, sob hipótese alguma se justifica traduzir pravum por mal no citado contexto, todavia, nos parece que o termo mais adequado é o disforme. Ou seja, um corpo não possui harmonia das partes quando é disforme, quando não dispõe da forma que deveria ter, quando é deformado enquanto comparado com os demais corpos da mesma espécie. Não estamos dissertando aqui sobre a simples diferença entre os corpos, ou entre os membros de um determinado corpo, pois ela em determinado grau é deveras harmoniosa. Mas quando essa diferença é grotesca, um corpo torna-se deformado com relação a outro corpo da mesma espécie, e as partes de um mesmo corpo se também possuem essa extrema diferença, igualmente são deformados, fazendo assim com que esse determinado ente nos desagrade, ou ofenda o nosso contemplar.

O texto também nos informa que não possui harmonia das partes, o corpo que é parum, e o que é nimium. Ou seja, um corpo não harmônico é aquele em que as partes são pequenas ou grandes demais. Em síntese poderíamos dizer que um corpo não é harmônico, quando em suas partes há uma desordem tal que o torna deformado, grande ou pequeno em demasia, quando comparado com os corpos da

como seriam sem deformações (Cf. De civ. Dei, XXII, 19, 1-3). É nesse contexto ele diz o que entende como beleza corpórea.

12 Omnis enim corporis pulchritudo est partium congruentia cum quadam coloris suavitate. Ubi autem non est partium congruentia, aut ideo quid offendit, quia pravum est, aut ideo quia parum, aut ideo quia nimium (De civ. Dei, XXII, 19, $2-P L 41)$.

${ }^{13}$ Referimos-nos a seguinte versão brasileira: AGOSTINHO, Santo. A Cidade de Deus: contra os pagãos. 4ed. Trad. de Oscar Paes Leme. Petrópolis: Vozes, São Paulo; Federação Agostiniana Brasileira, 1990. Parte II, Livro XXII, 19, 2.

BRANDÃO, Ricardo Evangelista. O belo enquanto congruentia partium: a harmonia na beleza sensível em Santo Agostinho. Griot : Revista de Filosofia, Amargosa, Bahia, v.16, n.2, p.322-333, dezembro/2017. 
mesma espécie, de maneira que esse desequilíbrio incomoda-nos em nosso ato de contemplar.

A coloris suavitate (suavidade de cor), presente em ambos os textos sob a nossa análise ${ }^{14}$, dita nesse contexto é muito mais um reforço da definição de beleza sensível que discutimos, que um acréscimo a ela. $O$ vocábulo suavitate pode ser traduzido como agradabilidade ou como suavidade, logo, o texto não está defendendo as cores claras ou pastéis como portadoras da beleza, mas, suavidade no sentido de ser uma cor agradável à nossa visão. Assim, quando as cores ou a cor de um determinado corpo, são ordenadas com certa conveniência, torna o objeto harmônico, e, por conseguinte colabora com a harmonia estética do objeto contemplado, auxiliando-o a torná-lo belo.

Portanto, a definição de beleza sensível que nos apresenta o pensador de Hipona nestes textos, é a de que o belo sensível é a harmonia, a harmonia das partes e das cores. Ou dizendo de outro modo, a beleza sensível está presente quando em determinado corpo ou ente sensível, seja nas suas partes ou em sua cor ou cores, estão tão convenientemente ordenadas que todo o conjunto se harmoniza, e essa harmonia agrada ao olhar do contemplador.

A citada definição é deveras ampla, de maneira que é preciso ser muito criativo para encontrar algum ser do mundo que não se encaixe nesta definição ao menos em algum grau. Essa amplitude conceitual se dá pela pressão do debate com os maniqueus. Só um conceito suficientemente amplo como este, hipoteticamente poderia abranger em certo sentido todo o cosmos, e eliminar a ideia de existência do feio natural, pois, segundo essa definição uma criatura teria que ser absolutamente despida de harmonia de cores e partes para ser feio. Como mesmo uma criatura muito deformada ainda teria em tese um grau mínimo de harmonia em sua deformação, é difícil imaginar como uma criatura do cosmos pode ser feia esteticamente falando. Mas, como a imaginação humana é deveras fértil, na hipótese de podermos imaginar um ente do cosmos sem o menor grau de harmonia, ainda não encontraríamos a fealdade no criado, pois, existe uma categoria estética ainda com maior amplitude, a unitas, que Agostinho teoriza em outros textos, e que não faz parte do escopo do presente artigo.

A definição supra analisada é tão ampla, que aquilo que era considerado apenas como aptum (conveniente) no De pulchro et apto, também é incluído no conceito de belo, visto que nessa obra o aptum é o que se adapta convenientemente interna ou externamente nos dando a aparência de beleza, internamente na conveniente relação entre as partes de um corpo, e externamente na relação apropriada de um corpo com um determinado adorno como um calçado ao pé (Cf. Conf., IV, 13, 20). Logo, na definição do hiponense pós maniqueu, o aptum também passa a estar incluído no belo, pois, neste caso, o aptum é uma das maneiras de expressão da congruentia partium, na medida em que o apropriado ou o conveniente nada mais é que uma relação harmoniosa presente no objeto percebido pelos sentidos que agrada o nosso olhar.

Como mencionamos no momento quando começamos a dissertar acerca da congruentia partium, não podemos afirmar que essa definição seja original em Santo

${ }^{14}$ Epist., III, 3, 4; De civ. Dei, XXII, 19,2.

BRANDÃO, Ricardo Evangelista. O belo enquanto congruentia partium: a harmonia na beleza sensível em Santo Agostinho. Griot : Revista de Filosofia, Amargosa, Bahia, v.16, n.2, p.322-333, dezembro/2017. 
Agostinho, pois, ela já estava presente integralmente em Cícero, e parcialmente em outros antigos ${ }^{15}$, como também com algumas variantes foi criticada por Plotino. $O$ filósofo Cícero eclético por excelência, unindo o estoicismo ao platonismo defende a tese de que o sentimento estético é o que distingui o homem dos animais não humanos, só o homem seria capaz de contemplar e admirar algo por sua beleza (Cf. DE BRUYNE, 1963, vol. I, p.191, 241). Nessa direção, o pensador romano ao dissertar acerca da diferença entre o corpo e a alma em sua Tusculanae Disputationes ${ }^{16}$, afirma o seguinte: "E como no corpo a conformação harmoniosa dos membros, acompanhada de certa suavidade de cor é nomeado de beleza, assim na alma chama-se beleza a uniformidade e o acordo da ideia com o juízo [...]" (Tusc., IV, 31$)^{17}$. Esteticamente, na maneira como se apresenta a citada definição Agostinho não se distingui do Tribuno, porém Cícero acrescenta em seu texto que essa beleza definida deve estar em total sintonia com a saúde do corpo (Cf. Tusc., IV, 30; DE BRUYNE, 1963, vol. I, p. 241). Nesse aspecto temos indício de a utilidade fazer parte do conceito de beleza corpórea ciceroniana, pois, a saúde serve justamente ao bom e apropriado funcionamento do corpo. Temos assim, a beleza do corpo como a harmonia das partes e das cores, com o adequado funcionamento do corpo (saúde).

Não temos competência para discutir se em Cícero o útil é o fundamento da beleza, ou se apenas não se põe em posição contrária ao belo, na medida em que toda a beleza associa-se a uma utilidade, mas, o que nos interessa aqui é o fato de que Santo Agostinho nos traz praticamente a mesma definição de beleza do Tribuno. $O$ que fará uma determinante diferença no hiponense são suas intenções de debater com os inimigos da fé cristã, entre eles os maniqueus, e sua fundamentação teórica da teologia cristã e da filosofia neoplatônica, fazendo com que essa definição tenha uma abrangência tal que acomode o feio, negando a sua existência. Logo, pensamos que o filósofo de Hipona tenha feito uso da definição de Cícero com um prisma neoplatônico cristão, pressionado pelas disputas que sempre o acompanharam e o motivaram na sua produção intelectual.

15 Essa definição já era corrente antes de Aristóteles, de forma que ele em seu Tópicos, ao dissertar acerca do que é melhor entre a saúde e o vigor e a beleza diz: "Também é melhor aquilo que é inerente às coisas melhores, anteriores ou dignas de maior reverência, como, por exemplo, a saúde é melhor que o vigor e a beleza, isto porque a saúde é inerente ao úmido, ao seco, ao quente e ao frio- numa palavra, a todos os elementos primários dos quais consiste o ser vivo, ao passo que o vigor e a beleza são inerentes aos elementos constitutivos secundários, uma vez que geralmente se admite que o vigor reside nas fibras nervosas e nos ossos, a beleza, por sua vez, consistindo numa certa simetria dos membros" (Top., III, 116b). Ou seja, Aristóteles dar a entender que a simetria das partes era a definição corrente em sua época para a beleza corpórea, e ele trabalha a diferença hierárquica entre a saúde e a beleza com base nessa definição.

16 Tusculanae Disputationes (Dicussões Tusculas) trata-se de uma obra do Tribuno Marcos Túlio Cícero (106- 43 a. C.), escrita nos últimos anos de sua vida, na vila de Túculo em 45 a. C. (Cf. FRAILE, 1997, tomo I, p. 657). A obra foi composta em formato de diálogo, organizada em cinco livros, em que seu título não exprime o conteúdo da obra, mas o ambiente em que foi escrita (Cf. DI VIRGINIO, 1962, p. IX). A despeito de seu conhecido ecletismo que seleciona ideias dos estóicos, epicureus, paripatéticos e acadêmicos, essa obra é claramente de orientação estóica, tratando assuntos como morte, dor, aflições e suas curas, felicidade, saúde, etc. (Ibid., p. XII, XIII, XVI - XX).

${ }^{17}$ "Et ut corporis est quaedam apta figura membrorum cum coloris quadam suavitate eaque dicitur pulchritudo, sic in animo opinionum iudiciorumque aequabilitas" (Tusc., IV, 31).

BRANDÃO, Ricardo Evangelista. O belo enquanto congruentia partium: a harmonia na beleza sensível em Santo Agostinho. Griot : Revista de Filosofia, Amargosa, Bahia, v.16, n.2, p.322-333, dezembro/2017. 
Quanto à relação entre a beleza corpórea e o útil que Cícero apresenta em sua Tusculanae Disputationes, na versão da definição apresentada por Agostinho, nos dois textos que analisamos não temos nenhuma referência. Isso não quer dizer que não seja possível nenhuma relação entre os dois conceitos, apenas que essa relação não é tratada aqui. De certa forma não podemos negar que tanto o belo como o útil sejam formas de manifestação do bem no cosmos. Visto que assim como o belo estético é um bem por agradar o criador, e para os homens que se aprazem com a contemplação de um cosmos harmônico, igualmente a utilidade das coisas na natureza para o homem e principalmente para o bom funcionamento da ordem cósmica, sem dúvida é um bem. Contudo, em se tratando da beleza esteticamente falando, embora não seja algo contrário a utilidade, pois, é possível um mesmo ente da natureza ser belo e também ser útil, são conceitos distintos. $\mathrm{E}$ a despeito do fato de que um belo coqueiro nos agrade esteticamente por sua beleza, pela harmônica disposição entre as suas palhas, tronco e cocos, e a sua sombra e água de coco ser bastante útil, a água do coco nos agradará em sua utilidade por um motivo totalmente distinto do prazer estético causado pela beleza. Assim sendo, no pensador bispo, ao separarmos o belo exclusivamente estético, esse belo nos agradará apenas por seus atributos estéticos, sem nenhuma relação necessária com a utilidade, visto serem perspectivas conceituais diferentes.

Em suma, na medida em que congruentia partium é uma categoria estética deveras ampla, categorias estéticas como a similitudine (semelhança) e aequelitas (igualdade) são contempladas por ela, ou melhor, estão contidas em seu amplo conceito. Destarte, poderíamos dizer que a semelhança e a simetria entre as partes são formas da harmonia entre as partes, logo, são belas graças à congruentia partium. Ou seja, a semelhança e a simetria entre as partes são belos, por serem harmônicos em sua semelhança e igualdade. Diante disto, poderíamos dizer que encontramos o fundamento da beleza sensível? Entendemos que a melhor maneira de responder as questões supracitadas, é afirmar que em certo sentido tanto similitudine, aequelitas como a congruentia partium estão envolvidas na essência da beleza, na medida em que são aspectos da categoria que possui essas três categorias estéticas citadas em maior grau, a categoria da unitas. Contudo, nos detendo especificamente à questão, pensamos que a harmonia entre as partes a despeito de ser uma categoria bem ampla e parcialmente respeitar o princípio todo o que foi criado por Deus é belo, não é capaz de contemplar criaturas simples, simplesmente porque o citado conceito bem como os demais são trabalhados para criaturas compostas de partes. Pois, a harmonia que é dita quando é utilizado a congruentia partium, é justamente a harmonia entre as diversas partes de um ente sensível. Só forçando muito o mencionado conceito podemos afirmar que mesmo uma criatura simples pode ter congruentia, pois, uma criatura também pode ter harmonia interna, todavia, devemos observar que essa harmonia dita neste sentido não é a congruentia partium que necessariamente envolverá uma composição de partes, mas apenas congruentia. Ao utilizarmos congruentia no último sentido mencionado, teremos de fato uma harmonia interna presente na simplicidade das criaturas, porém, harmonia nesse sentido nada mais é que a unidade interna. Desta forma, para evitar confusões conceituais, optamos por denominar essa harmonia que está presente nos entes compostos de partes e nos simples, como unidade.

BRANDÃO, Ricardo Evangelista. O belo enquanto congruentia partium: a harmonia na beleza sensível em Santo Agostinho. Griot : Revista de Filosofia, Amargosa, Bahia, v.16, n.2, p.322-333, dezembro/2017. 


\section{Referências bibliográficas}

AGUSTIN, San. Cartas (1º): 1-123. In: Obras completas de san Agustín. ed. bilíngüe Trad., introd. Y notas de Lope Cilleruelo. Madrid: La Editorial Catolica/BAC, 1986. tomo VIII, $940 \mathrm{p}$.

Del Génesis a la letra. In: Obras completas de san Agustín. ed. bilíngüe. Trad, introd. y notas de Balbino Martín. Madrid: La Editorial Catolica/BAC, 1957. tomo XV, p. 569-1271.

. Las confesiones. In: Obras completas de san Agustín. 9. ed. bilíngüe. Trad. de Angel Custodio Vega. Madrid: La Editorial Catolica/BAC, 2013. tomo II, 629 p.

La Trindad. In: Obras completas de san Agustín. ed. bilíngüe. Trad, introd. y notas de Luis Arias. Madrid: La Editorial Catolica/BAC, 1985. tomo V, 819 p.

. La ciudad de Dios (10 ). In: Obras completas de san Agustín. ed. bilíngüe. Trad. de Santos Sanatamarta del Rio y Miguel Lanero. Introd. general y notas de Victorino Capanaga. Madrid: La Editorial Catolica/BAC, 1988. tomo XVI, 840 p.

La ciudad de Dios (2० ). In: Obras completas de san Agustín. ed. bilíngüe. Trad. de Santos Sanatamarta del Rio y Miguel Lanero. Madrid: La Editorial Catolica/BAC, 2001. tomo XVII, 1070 p.

AgOSTINHO, Santo. A cidade de Deus: contra os pagãos. 4. ed. Trad. de Oscar Paes Leme. Petrópolis: Vozes; São Paulo: Federação Agostiniana Brasileira, 1990. parte II, 589 p. (Coleção Pensamento Humano).

ARISTÓTELES. Tópicos. In: Órganon. 2. ed. Tradução de Edson Bini. São Paulo: Edipro, 2010. p. 347-543.

CAPANAGA, Victorino. Introcuccion a los dialogos: principio, proceso y fin de la filosofia agustiniana. In: Obras completas de San Agustín. 6. ed. Trad., introd. y notas de Victorino Capanaga. Madrid: La Editorial Católica/BAC, 1994, v.1, p. 378-426.

CÍCERONE. Le Tusculane. edição bilíngüe Latim Italiano. Traduzione Ch. Labre. Milano: Arnolde Mondadori Editori, 1962.

COSTA, Marcos Roberto Nunes. Maniqueísmo: história, filosofia e religião. Petrópolis: Vozes, 2003. 175 p.

DE BRUYNE; Edgar. Historia de la estética: la antiguedad Griega y Romana. Trad. de Armando Suarez. Madrid: La Editorial Católica / BAC, 1963. tomo I, 486 p.

DI VIRGINIO, Adolfo. Introduzione. In: CÍCERONE. Le Tusculane. edição bilíngüe Latim Italiano. Traduzione Ch. Labre. Milano: Arnolde Mondadori Editori, 1962. p. I-XXXI.

FRAILE. Guillermo. Historia de la filosofia: Grecia y Roma. 7. ed. Madrid: BAC, 1997. tomo I, 852p.

PLOTINO. Enéadas. Introducciones, traducciones y notas de Jesús Igal. Madrid: Editorial Gredos, 1982. liv. I, II. 538p

PUECH, Henri-Charles. Sobre el maniqueísmo y otros ensayos. Traducción de María Cucurella Miquel. Madrid: Ediciones Siruela, 2006. p. 36).

RUBIO, Fernando Bermejo. El maniqueísmo: estudio introductorio. Madrid: Editorial Trotta, 2008. 299p.

; TORRENTS, José Montserrat. El maniqueísmo: textos y fuentes. Madrid: Editorial Trotta, 2008. 563p.

BRANDÃO, Ricardo Evangelista. O belo enquanto congruentia partium: a harmonia na beleza sensível em Santo Agostinho. Griot : Revista de Filosofia, Amargosa, Bahia, v.16, n.2, p.322-333, dezembro/2017. 
SARAIVA, F. R. dos Santos. Dicionário Latino - Potugês. Belo Horizonte: Livraria Garnier, 2006. 1.297p

Autor(a) para correspondência: Ricardo Evangelista Brandão, Instituto Federal de Pernambuco, Av. Prof. Luís Freire, 500, Cidade Universitária, CEP 50740-540, Recife - PE, Brasil. ricardobrand75@gmail.com 